\title{
Hepatocellular carcinoma occurs frequently and early after treatment in HCV genotype 3 infected persons treated with DAA regimens
}

Ghias Un Nabi Tayyab ${ }^{1,2}$, Shafqat Rasool ${ }^{1,2}$, Bilal Nasir ${ }^{1,2}$, Ghazala Rubi ${ }^{1,2}$, Abdul-Badi Abou-Samra ${ }^{3,4,5}$ and Adeel A. Butt $3,4,5^{*}$

\begin{abstract}
Background: There are conflicting data regarding the risk of hepatocellular carcinoma (HCC) after direct-acting antiviral agent (DAA) treatment. Risk of HCC in HCV genotype-3 infected persons after DAA therapy is not well known.

Methods: We prospectively studied HCV infected persons initiated on a DAA regimen between October 2014 and March 2017 at two centers in Pakistan. All persons were free of HCC at study initiation. HCC was confirmed based on characteristic CT scan findings. Patients were followed for 12 months after the completion of therapy.

Results: A total of 662 persons initiated treatment. Median age (IQR) was $50(41,57)$ years and $48.8 \%$ were male. At baseline, 49.4\% were cirrhotic, 91\% were genotype 3 and 91.9\% attained SVR. Treatment regimens used were: Sofosbuvir (SOF)/ribavirin (RBV)/pegylated interferon (PEG-IFN), 25.2\%; SOF/RBV, 62.4\%; SOF/RBV/daclatasavir (DCV), 10.6\%; SOF/DCV, 2.0\%. Incident HCC was detected in 42 patients (12.8\%) in the 12-month period after treatment completion and was exclusively observed in those with cirrhosis. In multivariable Cox regression analysis, SVR was associated with a reduction in $\mathrm{HCC}$ risk (HR, 95\% Cl: $0.35,0.14,0.85)$. In Kaplan-Meier plots by treatment regimen, those treated with SOF/RBV, SOF/RBV/DCV, or SOF/DCV regimens had a shorter HCC-free survival compared with those treated with a SOF/RBV/PEG-IFN regimen.
\end{abstract}

Conclusion: In a predominantly genotype 3 cohort, incident HCC occurred frequently and early after treatment completion, and exclusively in those with pre-treatment cirrhosis. SVR reduced the risk of HCC. Treating HCV infected persons before development of cirrhosis may reduce risk of HCC.

Keywords: Hepatocellular carcinoma, HCV genotype 3, DAA, Pakistan

\footnotetext{
* Correspondence: aab2005@gatar-med.cornell.edu

${ }^{3}$ Weill Cornell Medical College, New York, NY, USA

${ }^{4}$ Weill Cornell Medical College, Doha, Qatar

Full list of author information is available at the end of the article
}

C C The Author(s). 2020 Open Access This article is licensed under a Creative Commons Attribution 4.0 International License, which permits use, sharing, adaptation, distribution and reproduction in any medium or format, as long as you give appropriate credit to the original author(s) and the source, provide a link to the Creative Commons licence, and indicate if changes were made. The images or other third party material in this article are included in the article's Creative Commons licence, unless indicated otherwise in a credit line to the material. If material is not included in the article's Creative Commons licence and your intended use is not permitted by statutory regulation or exceeds the permitted use, you will need to obtain permission directly from the copyright holder. To view a copy of this licence, visit http://creativecommons.org/licenses/by/4.0/. The Creative Commons Public Domain Dedication waiver (http://creativecommons.org/publicdomain/zero/1.0/) applies to the data made available in this article, unless otherwise stated in a credit line to the data. 


\section{Background}

Treatment of hepatitis $\mathrm{C}$ virus (HCV) has been revolutionized by the use of direct acting antiviral agents (DAAs) against HCV. These regimens are more efficacious compared with the older interferon based regimens, with sustained virologic response (SVR) rates consistently exceeding 90-95\% [1-5]. Their general safety profile and tolerability is well established in randomized clinical trials and large real-world studies [6-8]. Other clear benefits of DAA-based regimens include reduction in overall mortality, reduced risk of non-liver cancers, and reduction in incidence of several extrahepatic complications including diabetes, stroke and cardiovascular disease events [9-13]. Some earlier reports suggested an association between the newer DAA-based regimens and reactivation of hepatitis $B$ virus (HBV) infection, progression of chronic kidney disease, and early hepatic decompensation events $[14,15]$. However, larger studies in a variety of settings, and with appropriate control groups have not corroborated these associations [7, 8, 16-19]. The association of DAA-regimens with hepatocellular carcinoma (HCC) is less clear. Multiple reports have suggested an increased incidence of $\mathrm{HCC}$ in persons treated with DAA-based regimens [20-22]. However, most of this risk was attributed to recurrence of previously treated HCC. Several other studies have found no association between DAA-based regimens and risk of incident HCC [17, 23-25]. Pakistan has one of highest rates of HCV infection, mostly associated with unsafe injection practices $[26,27]$. The predominant genotype In Pakistan is genotype 3 infection, accounting for $66-72 \%$ of the infected persons [28, 29]. Newer DAA-based regimens are now widely available in Pakistan, and $>90 \%$ persons with HCV genotype 3 infection treated with these regimens attain SVR [30]. The risk of HCC among persons with HCV genotype 3 infection who are treated with newer DAA-based regimens is unknown. We undertook this to determine the association between DAA-based regimen and incident HCC in a predominantly $\mathrm{HCV}$ genotype 3 population in Pakistan.

\section{Methods}

\section{Study setting and participants}

We prospectively enrolled adult persons with HCV infection who were initiated on a DAA-based regimen between October 2014 and March 2017 at two centers in urban Pakistan. All consecutive persons who provided informed consent, were eligible for the study and free of HCC were enrolled. At baseline, a detailed history, physical examination and laboratory evaluation was performed. Liver imaging (high quality ultrasound) and serum alfa fetoprotein (AFP) levels were performed to rule out $\mathrm{HCC}$ at baseline. Treatment for $\mathrm{HCV}$ was initiated based on preferred regimens listed in the national guidelines and regimen availability at the treating center [31]. All enrolled persons were followed at monthly intervals during the course of treatment and for 24 weeks after completion of treatment, and at threemonthly intervals thereafter for at least 12 months after treatment completion. Clinical assessment, AFP levels and liver ultrasound were performed at the three-month visits. Any new hepatic decompensation event, new liver nodule on ultrasound, or an AFP increase of $>10 \mathrm{IU} / \mathrm{mL}$ were followed up by a dynamic computerized tomographic (CT) scan of the liver to rule out HCC.

\section{Definitions}

Our primary endpoint was incident HCC, which was diagnosed on the basis of characteristic findings on CT scan of the liver during the 12 months follow up after completion of treatment. Sustained virologic response was defined as undetectable HCV RNA 12 or more weeks after completion of treatment. Presence of liver cirrhosis was determined using characteristic liver imaging findings (ultrasound or CT scan) and transient elastography using a cutoff of $12.5 \mathrm{kPa}$. Comorbidities were diagnosed by participant self-report.

\section{Statistical analyses}

Baseline clinical characteristics were compared for persons with and without incident HCC. Mean $( \pm$ standard deviation) or median (interquartile range) were calculated for normally and non-normally distributed continuous data respectively. Multivariable Cox proportional hazards analysis was used to determine the predictors of incident HCC. Assumptions of proportionality were ascertained using Schoenfeld residuals. Kaplan-Meier curves were generated to demonstrate time to diagnosis of HCC by attainment of SVR, and HCC-free survival by treatment regimen. Log-rank test was used to determine statistical significance of the difference, with $p$-value of $<0.05$ considered as a statistically significant difference.

\section{Ethical considerations}

Institutional approvals were obtained at each site prior to study initiation. All participants provided informed consent prior to entry into the study.

\section{Results}

A total of 662 participants were included in the study. The median age was 50 years (inter-quartile range 41,57 ) and $48.8 \%$ were male. (Table 1 ) Mean weight of the participants was $71.8 \mathrm{~kg}$ (standard deviation 13.1), 6.9\% had hypertension, $28.2 \%$ had diabetes and $1.4 \%$ were coinfected with hepatitis B virus. Overall, 90.8\% had HCV genotype 3 infection and $49.4 \%$ had cirrhosis $(89.3 \%$ 
Table 1 Baseline characteristics. $N=662$

\begin{tabular}{|c|c|}
\hline Variable & Result \\
\hline Median age in years, IQR & $50(41,57)$ \\
\hline Sex, \% male & 48.79 \\
\hline Weight, mean (SD) kg & $71.8(13.1)$ \\
\hline Obesity (\% obese) & 16.62 \\
\hline Hypertension, \% & 6.95 \\
\hline Diabetes, \% & 28.25 \\
\hline Hepatitis B virus coinfection & 1.36 \\
\hline Cirrhosis, overall \% & 49.40 \\
\hline Cirrhosis compensated, \% & 89.27 \\
\hline Cirrhosis decompensated, \% & 10.73 \\
\hline HCV RNA, median $\log _{10} \mathrm{IU} / \mathrm{mL}(\mathrm{IQR})$ & $5.90(5.20,6.45)$ \\
\hline \multicolumn{2}{|l|}{ HCV genotype } \\
\hline HCV genotype 3 & 90.79 \\
\hline HCV genotype non-3 & 9.21 \\
\hline Sustained virologic response, $\%$ & 91.90 \\
\hline Incident HCC, \% & 6.34 \\
\hline Median time to HCC, weeks (IQR) & $28(21,39)$ \\
\hline \multicolumn{2}{|l|}{ Treatment regimen, \% } \\
\hline SOF/RBV/PEG-IFN & 25.23 \\
\hline SOF/RBV & 62.24 \\
\hline SOF/DCV/RBV & 10.57 \\
\hline SOF/DCV & 1.96 \\
\hline
\end{tabular}

IQR inter-quartile range, $H C C$ hepatocellular carcinoma, SOF sofosbuvir, RBV ribavirin, $P E G-I F N$ pegylated interferon, $D C V$ daclatasvir;

compensated cirrhosis; $10.7 \%$ decompensated cirrhosis). All treatment regimens included sofosbuvir (SOF) plus at least one other agent (ribavirin [RBV], pegylated interferon [PEG-IFN], daclatasvir [DCV]; Table 1). Sustained virologic response was attained in $91.9 \%$ of participants. A total of 42 cases of HCC were observed in the 12month post-treatment period, with a median time to first diagnosis of 28 weeks (IQR 21,39). Baseline characteristics of those with and without HCC are presented in Table 2. Of note, all persons with incident HCC had prevalent liver cirrhosis.

Increasing age was associated with a higher risk of incident HCC (HR 1.75; 95\% CI 1.29,2.37) in Cox proportional hazards analysis. (Table 3) While the hazards ratios for all DAA-based regimens demonstrated a higher risk compared with SOF/PEG-IFN/RBV regimen, only SOF/DCV/RBV regimen was statistically significantly associated with a higher risk of incident HCC. However, the $95 \%$ confidence intervals for all hazards ratios were very wide, making an assumption of true association relatively difficult. Sustained virologic response was associated with a significant reduction in the risk of incident HCC (HR 0.35, 95\% CI 0.14,0.85).
In Kaplan-Meier analysis, time to first HCC diagnosis was not different among those who attained SVR vs. those who did not. (Fig. 1a; log-rank $p$-value $=0.3$ ) Hepatocellular carcinoma-free survival was significantly different between various DAA-based treatment regimens. (Fig. 1b The combination regimen including PEGIFN and RBV had significantly longer HCC-free survival compared with other DAA-based regimens without PEG-IFN/RBV.

\section{Additional analyses}

There were 9 persons with HBV coinfection. We repeated all analyses after removing those 9 persons with HBV coinfection. Baseline characteristics of the updated cohort $(N=653)$ are presented in supplementary Table 1. After removing the 9 persons with HBV coinfection, 40 persons had a diagnosis of HCC. Baseline characteristics of these 40 persons with HCC and 613 persons without $\mathrm{HCC}$ are presented in supplementary Table 2. Finally, the predictors of development of HCC in the updated cohort are presented in supplementary Table 3. All results in the updated cohort were similar to the main results.

\section{Discussion}

In this large study of persons with predominantly $\mathrm{HCV}$ genotype 3 infection, incident HCC was observed frequently and early after completion of treatment with a DAA-based regimen.

The association between DAA-based regimens and development of $\mathrm{HCC}$ is complicated and poorly understood. Early uncontrolled studies suggested a higher risk of HCC in persons treated with DAA regimens, which was more pronounced for recurrence of HCC after previous successful treatment rather than de novo development of HCC. More recent larger studies with improved design and appropriate control groups have failed to substantiate this association. In fact, DAA-based regimens have been associated with a similar or reduced risk of incident or de novo HCC when compared with untreated persons or those treated with older interferon-based regimens [17, 23, 32]. There are scant and conflicting data regarding the risk of de novo HCC in persons with HCV genotype 3 infection who are treated with DAA-based regimens. While at least one study has reported a lower incidence of $\mathrm{HCC}$ in persons with HCV non-genotype 1 infection, another large national study observed a clear association between HCV genotype 3 infection and HCC cirrhosis [33,34]. Neither studies addressed the role of DAA-based regimens upon the risk of HCC. In our analysis, HCV genotype 3 infected persons treated with a DAA-based regimen were at a higher numerical risk of incident $\mathrm{HCC}$, though this 
Table 2 Baseline characteristics of persons with and without incident HCC

\begin{tabular}{|c|c|c|c|}
\hline Variable & With HCC $(N=42)$ & Without HCC & $P$-value \\
\hline Mean age, (SD) & $57.4(8.4)$ & $48.6(11.3)$ & $<0.0001$ \\
\hline Median age, IQR & $58(53,65)$ & $50(40,56)$ & $<0.0001$ \\
\hline Sex, $\%$ male & $45.24 \%$ & $49.03 \%$ & 0.63 \\
\hline Weight, mean (SD) kg & $67.4(13)$ & $72.1(13)$ & 0.02 \\
\hline Obesity (\% obese) & $11.90 \%$ & $16.93 \%$ & 0.40 \\
\hline Hypertension, \% & $7.14 \%$ & $6.93 \%$ & 0.96 \\
\hline Diabetes, \% & $47.60 \%$ & $26.90 \%$ & 0.004 \\
\hline Hepatitis B virus coinfection & $0.30 \%$ & $1.06 \%$ & 0.09 \\
\hline Cirrhosis, \% & $100.00 \%$ & $45.97 \%$ & $<0.0001$ \\
\hline Cirrhosis decompensated, \% & $30.95 \%$ & $9.35 \%$ & $<0.0001$ \\
\hline HCV RNA, median $\log _{10} \mathrm{IU} / \mathrm{mL}$ (IQR) & $6.30(5.84,6.51)$ & $5.87(5.20,6.45)$ & 0.24 \\
\hline HCV genotype 3 & 95.2 & 90.5 & 0.41 \\
\hline Sustained virologic response, $\%$ & 87.5 & 92.2 & 0.29 \\
\hline Median time to HCC, weeks (IQR) & $28(21,39)$ & $\mathrm{N} / \mathrm{A}$ & - \\
\hline Treatment regimen, \% & & & 0.0006 \\
\hline SOF/RBV/PEG-IFN & 2.4 & 26.8 & \\
\hline SOF/RBV & 71.4 & 61.6 & \\
\hline SOF/DCV/RBV & 23.8 & 9.7 & \\
\hline SOF/DCV & 2.4 & 1.9 & \\
\hline
\end{tabular}

IQR inter-quartile range, HCC hepatocellular carcinoma, SOF sofosbuvir, RBV ribavirin, PEG-IFN pegylated interferon, DCV daclatasvir;

association did not reach statistical significance. This is perhaps due to the small number of persons with non-genotype 3 infection. Future studies with larger comparison group with non-genotype 3 infection may help clarify this association.

All cases of HCC were observed in those with prevalent cirrhosis. This is consistent with some previous studies, though other studies have clearly demonstrated that HCC can occur in the absence of pre-existing cirrhosis [35]. Regardless, persons with cirrhosis constitute the highest risk group for development of $\mathrm{HCC}$ and require regular and frequent screening for HCC. Additionally, an association between metabolic factors, particularly diabetes, has been reported in many studies [36]. Curiously, a protective effect has been demonstrated with higher weight. Our study shows a higher

Table 3 Predictors of development of hepatocellular carcinoma (multivariable Cox regression model)

\begin{tabular}{lll}
\hline Variable & HR $(95 \% \mathrm{Cl})$ & $P$-value \\
\hline Age, per 10 year increase & $1.75(1.29,2.37)$ & 0.0003 \\
Male sex & $1.21(0.63,2.35)$ & 0.57 \\
Weight, each $5 \mathrm{~kg}$ increase & $0.83(0.73,0.96)$ & 0.01 \\
Hypertension & $1.01(0.3,3.42)$ & 0.99 \\
Diabetes & $1.46(0.76,2.79)$ & 0.26 \\
HCV genotype 3 (comparator genotype non-3) & $1.42(0.34,5.99)$ & 0.64 \\
Sustained virologic response & $0.35(0.14,0.85)$ & 0.02 \\
Treatment regimen & & \\
$\quad$ SOF/RBV/PEG-IFN (comparator) & & 0.06 \\
$\quad$ SOF/RBV & $6.75(0.89,51.1)$ & 0.01 \\
$\quad$ SOF/DCV/RBV & $17.32(2.14,140.36)$ & 0.13 \\
$\quad$ SOF/DCV & $8.63(0.53,141.25)$ &
\end{tabular}



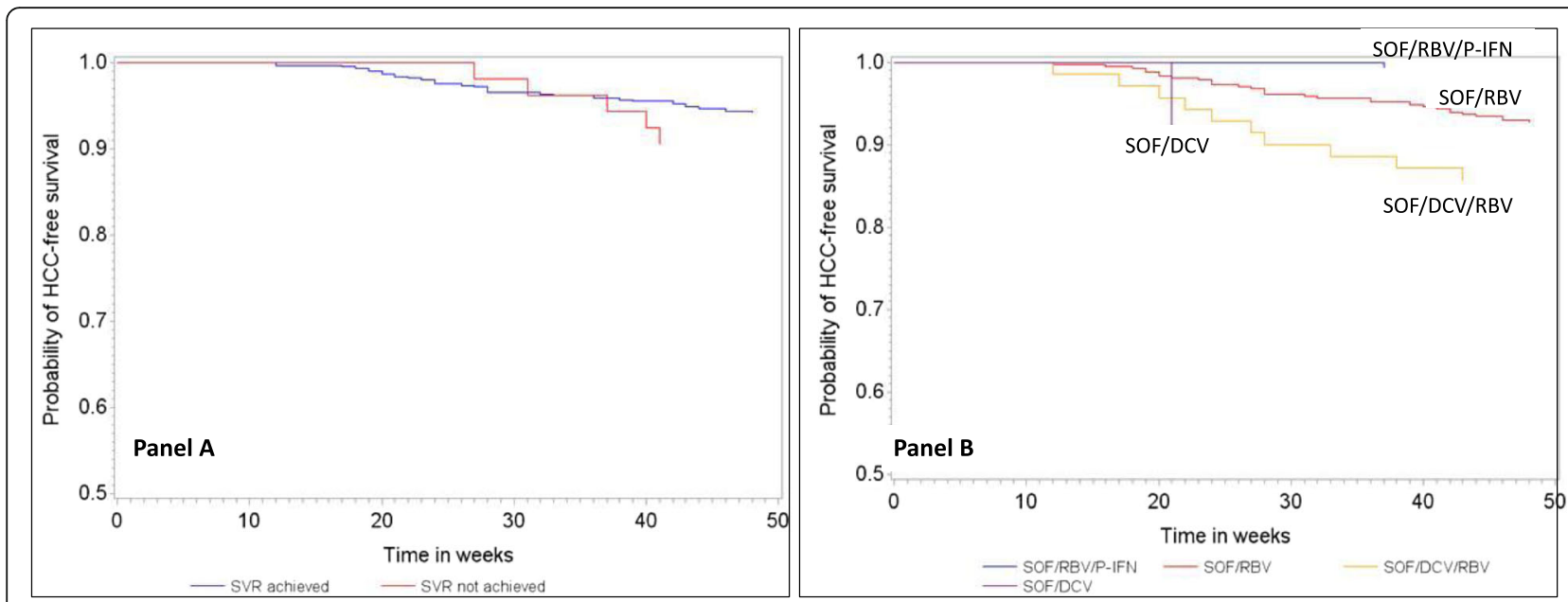

Panel A. P-value for hepatocellular carcinoma free survival: SVR achieved vs. SVR not achieved $=0.3$

\begin{tabular}{|l|c|c|c|}
\hline \multicolumn{4}{|c|}{ Panel B. P-values for hepatocellular carcinoma free survival } \\
\hline & SOF/RBV & SOF/DCV/RBV & SOF/DCV \\
\hline SOF/RBV/P-IFN & 0.001 & $<.0001$ & 0.02 \\
\hline SOF/RBV & -- & 0.04 & 0.94 \\
\hline SOF/DCV/RBV & -- & -- & 0.54 \\
\hline
\end{tabular}

Fig. 1 Kaplan-Meier curves showing time to hepatocellular carcinoma by attainment of SVR (a), and hepatocellular carcinoma free survival by treatment regimen (b)

risk of $\mathrm{HCC}$ in persons with diabetes, though this did not reach statistical significance, and a lower risk of HCC with increasing weight. Apparent protective effect of increasing weight may be the result of a "healthy person" phenomenon where persons with normal or increased weight are less likely to have chronic underlying diseases; conversely, weight loss in persons with HCC may have unmasked this spurious association.

The benefit of attaining SVR is clearly described in literature. Clearance of the virus from circulation, as evidenced by undetectable HCV RNA, is associated with reduced mortality and a reduced risk of several complications $[9,10,12,13,32,37-39]$. We found the attainment of SVR to be strongest protective factor against development of HCC. This underscores the need for increasing access to early and effective treatment, with multiple anticipated benefits.

The role of specific regimen(s) upon the risk of incident HCC is less clear. While we observed a higher risk among persons treated with SOF/DCV/RBV compared with SOF/PEG-IFN/RBV regimen, the 95\% confidence interval was very wide (HR 17.32; 95\% CI 2.14,140.36) to make any clinical practice change recommendations. The risk with other regimens (SOF/RBV; SOF/DCV/ $\mathrm{RBV}$; SOF/DCV) was also high, but these associations did not reach statistical significance. Possible reasons for a lower observed risk in persons treated with an interferon-containing regimen could be lesser fibrosis in these persons, inherent immune modulating property of interferon, or other differences in baseline characteristics of patients. Whether inclusion of PEG-IFN reduces the risk of HCC in persons with HCV genotype 3 infection warrants further study.

Screening for HCC is critical in persons with $\mathrm{HCV}$ and cirrhosis, though some persons may develop HCC in the absence of cirrhosis. Alfa fetoproteion levels and liver imaging are often used to screen patients for HCC. While computed tomography or magnetic resonance imaging are more sensitive and specific for HCC, ultrasound is cheaper and more readily available, particularly in resource limited settings. The sensitivity of ultrasound varies from 84 to $94 \%$ for all stage $\mathrm{HCC}$ and $47-63 \%$ for early stage HCC $[40,41]$. Addition of AFP has been shown to increase sensitivity in some, but noth other studies. It is potentially possible that some of the early detected tumors in our study subjects were actually present even before treatment started and were not recognized by our screening techniques.

The strengths of our study include its prospective design and large number of participants. Limitations include a small non-genotype 3 comparison group, lack of validated measures of certain other risk factors for HCC, e.g. non-alcoholic fatty liver disease, aflatoxin exposure. It must also be noted that the treatment regimens used during the study time period do not conform with the most recent treatment guidelines, though the overall efficacy and benefits of treatment are still valid.

\section{Conclusions}

In conclusion, persons with HCV genotype 3 infection treated with DAA-based regimens experience frequent and early occurrence of de novo HCC after completion 
of treatment. The risk is exclusively observed in those with existing liver cirrhosis. Attainment of SVR significantly reduces that risk. The role of specific DAA-based regimens upon this risk is less clear and warrants further study. Persons with HCV genotype 3 infection treated with DAA-based regimens, particularly those with cirrhosis, should be screened for HCC early and frequently after completion of treatment.

\section{Supplementary information}

Supplementary information accompanies this paper at https://doi.org/10. 1186/s12876-020-01249-4.

Additional file 1 Supplementary Table 1. Baseline characteristics excluding 9 persons with hepatitis B virus coinfection. Supplementary

Table 2. Baseline characteristics of persons with and without incident HCC excluding 9 persons with hepatitis B virus coinfection.

Supplementary Table 3. Predictors of development of HCC

(multivariable Cox regression model) excluding 9 persons with hepatitis B virus coinfection.

\section{Abbreviations}

AFP: Alfa fetoprotein; CT: Computerized tomographic scan; DAA: Direct acting antiviral agents; DCV: Daclatasvir; HBV: Hepatitis B virus; HCC: Hepatocellular carcinoma; HCV: Hepatitis C virus; PEG-IFN: Pegylated interferon; RBV: Ribavirin; SOF: Sofosbuvir; SVR: Sustained virologic response

\section{Acknowledgements}

N/A

\section{Authors' contributions}

All authors have read and approved the manuscript. Study concept and design: GNT Data collection: GNT, SR, BN Data analysis and interpretation: $A A B, G N T, G R$ Critical review of the manuscript for important intellectual content: GNT, SR, BN, GR, A-B A-S, AAB, GNT had access to data at all times and assumes responsibility for the conduct of the study.

\section{Funding}

There was no funding available for this study.

\section{Availability of data and materials}

Subject level data are not available to the public. Aggregate data may be shared if all regulatory and legal approvals have been obtained by the requesting entity/person(s). Contact the corresponding author (Adeel A. Butt) with any request along with approvals.

\section{Ethics approval and consent to participate}

Ethics Committee at Post Graduate Medical Institute, Ameer Ud Din Medical College, Lahore, Pakistan approved the study. (No document number assigned) All participants provided written informed consent.

\section{Consent for publication}

N/A (No identifying information or images of participants have been used in this publication)

\section{Competing interests}

The authors declare that they have no competing interests.

\section{Author details}

${ }^{1}$ Post Graduate Medical Institute, Ameer Ud Din Medical College, Lahore, Pakistan. ${ }^{2}$ Lahore General Hospital, Lahore, Pakistan. ${ }^{3}$ Weill Cornell Medical College, New York, NY, USA. ${ }^{4}$ Weill Cornell Medical College, Doha, Qatar. ${ }^{5}$ Hamad Medical Corporation, Doha, Qatar.
Received: 24 October 2019 Accepted: 27 March 2020

Published online: 06 April 2020

\section{References}

1. Afdhal N, Zeuzem S, Kwo P, et al. Ledipasvir and sofosbuvir for untreated HCV genotype 1 infection. N Engl J Med. 2014;370:1889-98.

2. Afdhal N, Reddy KR, Nelson DR, et al. Ledipasvir and sofosbuvir for previously treated HCV genotype 1 infection. N Engl J Med. 2014;370:148393.

3. Sulkowski MS, Gardiner DF, Rodriguez-Torres M, et al. Daclatasvir plus sofosbuvir for previously treated or untreated chronic HCV infection. N Engl J Med. 2014;370:211-21.

4. Butt AA, Yan P, Shaikh OS, Chung RT, Sherman KE. study E. Treatment adherence and virological response rates in hepatitis $C$ virus infected persons treated with sofosbuvir-based regimens: results from ERCHIVES. Liver Int. 2016;36:1275-83.

5. Butt AA, Yan P, Shaikh OS, Chung RT, Sherman KE. Sofosbuvir-based regimens in clinical practice achieve SVR rates closer to clinical trials: results from ERCHIVES. Liver Int. 2016:36:651-8.

6. Ioannou GN, Beste LA, Chang MF, et al. Effectiveness of Sofosbuvir, Ledipasvir/Sofosbuvir, or Paritaprevir/Ritonavir/Ombitasvir and Dasabuvir Regimens for Treatment of Patients With Hepatitis C in the Veterans Affairs National Health Care System. Gastroenterology. 2016;151:457-71.e5.

7. Butt AA, Ren Y, Marks K, Shaikh OS, Sherman KE. Do directly acting antiviral agents for HCV increase the risk of hepatic decompensation and decline in renal function? Results from ERCHIVES. Aliment Pharmacol Ther. 2017:45: 150-9.

8. Butt AA, Ren Y, Puenpatom A, Arduino JM, Kumar R, Abou-Samra AB. Effectiveness, treatment completion and safety of sofosbuvir/ledipasvir and paritaprevir/ritonavir/ombitasvir + dasabuvir in patients with chronic kidney disease: an ERCHIVES study. Aliment Pharmacol Ther. 2018;48:35-43.

9. Backus LI, Belperio PS, Shahoumian TA, Mole LA. Impact of sustained Virologic response with direct-acting antiviral treatment on mortality in patients with advanced liver disease. Hepatology. 2019;69:487-97.

10. Mahale $P$, Engels $E A$, Li $R$, et al. The effect of sustained virological response on the risk of extrahepatic manifestations of hepatitis $C$ virus infection. Gut. 2018:67:553-61.

11. Masarone M, Persico M. Hepatitis C virus infection and non-hepatocellular malignancies in the DAA era: a systematic review and meta-analysis. Liver Int. 2019;39:1292-306.

12. Butt AA, Yan P, Shuaib A, Abou-Samra AB, Shaikh OS, Freiberg MS. Directacting antiviral therapy for HCV infection is associated with a reduced risk of cardiovascular disease events. Gastroenterology. 2019;156:987-96 e8.

13. Butt AA, Yan P, Aslam S, Shaikh OS, Abou-Samra AB. Hepatitis C Virus (HCV) treatment with directly acting agents reduces the risk of incident diabetes: results from electronically retrieved cohort of HCV infected veterans (ERCHIVES). Clin Infect Dis. 2020;70:1153-60

14. Stine JG, Intagliata N, Shah NL, et al. Hepatic decompensation likely attributable to simeprevir in patients with advanced cirrhosis. Dig Dis Sci. 2015;60:1031-5

15. Collins JM, Raphael $\mathrm{KL}$, Terry $C$, et al. Hepatitis B virus reactivation during successful treatment of hepatitis $C$ virus with Sofosbuvir and Simeprevir. Clin Infect Dis. 2015;61:1304-6.

16. Gane E, Lawitz E, Pugatch D, et al. Glecaprevir and Pibrentasvir in patients with HCV and severe renal impairment. N Engl J Med. 2017;377:1448-55.

17. Li DK, Ren Y, Fierer DS, et al. The short-term incidence of hepatocellular carcinoma is not increased after hepatitis $C$ treatment with direct-acting antivirals: an ERCHIVES study. Hepatology. 2018;67:2244-53.

18. Sulkowski MS, Chuang WL, Kao JH, et al. No evidence of reactivation of hepatitis B virus among patients treated with Ledipasvir-Sofosbuvir for hepatitis C virus infection. Clin Infect Dis. 2016;63:1202-4.

19. Belperio PS, Shahoumian TA, Mole LA, Backus LI. Evaluation of hepatitis B reactivation among 62,920 veterans treated with oral hepatitis $C$ antivirals. Hepatology. 2017:66:27-36

20. Conti F, Buonfiglioli F, Scuteri A, et al. Early occurrence and recurrence of hepatocellular carcinoma in HCV-related cirrhosis treated with direct-acting antivirals. J Hepatol. 2016:65:727-33.

21. Reig M, Marino Z, Perello C, et al. Unexpected high rate of early tumor recurrence in patients with HCV-related HCC undergoing interferon-free therapy. J Hepatol. 2016;65:719-26. 
22. Flisiak $R$, Janczewska E, Lucejko $M$, et al. Durability of virologic response, risk of de novo hepatocellular carcinoma, liver function and stiffness 2 years after treatment with ombitasvir/paritaprevir/ritonavir+/-dasabuvir+/ -ribavirin in the AMBER, real-world experience study. J Viral Hepat. 2018;25: 1298-305.

23. Huang $\mathrm{P}$, Liu M, Zang F, et al. The development of hepatocellular carcinoma in HCV-infected patients treated with DAA: a comprehensive analysis. Carcinogenesis. 2018;39:1497-505.

24. Nahon P, Layese R, Bourcier V, et al. Incidence of Hepatocellular Carcinoma After Direct Antiviral Therapy for HCV in Patients With Cirrhosis Included in Surveillance Programs. Gastroenterology. 2018;155:1436-50.e6.

25. Calvaruso V, Cabibbo G, Cacciola I, et al. Incidence of Hepatocellular Carcinoma in Patients With HCV-Associated Cirrhosis Treated With DirectActing Antiviral Agents. Gastroenterology. 2018;155:411-21.e4.

26. Pasha O, Luby SP, Khan AJ, Shah SA, McCormick JB, Fisher-Hoch SP. Household members of hepatitis C virus-infected people in Hafizabad Pakistan: infection by injections from health care providers. Epidemiol Infect. 1999;123:515-8.

27. Luby SP, Qamruddin K, Shah AA, et al. The relationship between therapeutic injections and high prevalence of hepatitis C infection in Hafizabad, Pakistan. Epidemiol Infect. 1997;119:349-56.

28. Ul Abideen Z, Siddique S, Nasrullah I, et al. A 2-year retrospective study of viral and host-associated risk factors in Pakistani hepatocellular carcinoma patients. Eur J Gastroenterol Hepatol. 2019;31:1103-9.

29. Waqar $M$, Khan $\mathrm{AU}$, Rehman HU, et al. Determination of hepatitis $\mathrm{C}$ virus genotypes circulating in different districts of Punjab (Pakistan). Eur J Gastroenterol Hepatol. 2014;26:59-64.

30. Sarwar S, Tarique S, Aleem A, Khan AA. Effect of adding daclatasvir in sofosbuvir-based therapy in genotype 3 hepatitis C: real-world experience in Pakistan. Eur J Gastroenterol Hepatol. 2019;31:1035-9.

31. Umar M, Khaar HT, Akhter TS, et al. Diagnosis, management and prevention of hepatitis C in Pakistan 2017. J Ayub Med Coll Abbottabad. 2016;28:S839s82.

32. Kanwal F, Kramer J, Asch SM, Chayanupatkul M, Cao Y, El-Serag HB. Risk of Hepatocellular Cancer in HCV Patients Treated with Direct Acting Antiviral Agents. Gastroenterology. 2017;153(4):996-1005. https://doi.org/10.1053/j. gastro.2017.06.012. Epub 2017 Jun 19. PMID:2864219.

33. Roffi L, Redaelli A, Colloredo G, et al. Outcome of liver disease in a large cohort of histologically proven chronic hepatitis C: influence of HCV genotype. Eur J Gastroenterol Hepatol. 2001;13(5):501-6.

34. Kanwal F, Kramer JR, llyas J, Duan Z, El-Serag HB. HCV genotype 3 is associated with an increased risk of cirrhosis and hepatocellular cancer in a national sample of U.S. Veterans with HCV. Hepatology. 2014;60:98-105.

35. Mittal S, El-Serag HB, Sada YH, et al. Hepatocellular Carcinoma in the Absence of Cirrhosis in United States Veterans is Associated With Nonalcoholic Fatty Liver Disease. Clin Gastroenterol Hepatol. 2016;14:12431.e1

36. Lai SW, Chen PC, Liao KF, Muo CH, Lin CC, Sung FC. Risk of hepatocellular carcinoma in diabetic patients and risk reduction associated with antidiabetic therapy: a population-based cohort study. Am J Gastroenterol. 2012;107:46-52.

37. Morgan RL, Baack B, Smith BD, Yartel A, Pitasi M, Falck-Ytter Y. Eradication of hepatitis $C$ virus infection and the development of hepatocellular carcinoma: a meta-analysis of observational studies. Ann Intern Med. 2013; 158:329-37.

38. Nahon P, Bourcier V, Layese $R$, et al. Eradication of Hepatitis C Virus Infection in Patients With Cirrhosis Reduces Risk of Liver and Non-Liver Complications. Gastroenterology. 2017;152:142-56.e2.

39. Cacoub P, Nahon P, Layese R, et al. Prognostic value of viral eradication for major adverse cardiovascular events in hepatitis $C$ cirrhotic patients. Am Heart J. 2018;198:4-17.

40. Tzartzeva K, Obi J, Rich NE, et al. Surveillance Imaging and Alpha Fetoprotein for Early Detection of Hepatocellular Carcinoma in Patients With Cirrhosis: A Meta-analysis. Gastroenterology. 2018;154:1706-18.e1.

41. Singal A, Volk ML, Waljee A, et al. Meta-analysis: surveillance with ultrasound for early-stage hepatocellular carcinoma in patients with cirrhosis. Aliment Pharmacol Ther. 2009;30:37-47.

\section{Publisher's Note}

Springer Nature remains neutral with regard to jurisdictional claims in published maps and institutional affiliations.

\section{Ready to submit your research? Choose BMC and benefit from:}

- fast, convenient online submission

- thorough peer review by experienced researchers in your field

- rapid publication on acceptance

- support for research data, including large and complex data types

- gold Open Access which fosters wider collaboration and increased citations

- maximum visibility for your research: over $100 \mathrm{M}$ website views per year

At BMC, research is always in progress.

Learn more biomedcentral.com/submissions 